\title{
NEW OBSERVATIONS OF MATERNAL CARE \\ EXHIBITED BY THE GREEN LYNX SPIDER, PEUCETIA VIRIDANS HENTZ (ARANEIDA:OXYOPIDAE) ${ }^{1}$
}

\author{
BY JOHN B. RANDALL \\ Dept. of Entomology and Nematology \\ University of Florida \\ Gainesville, Florida 32611
}

\section{INTRODUCTION}

Maternal care of young is found in various families of spiders, most notably the lycosids (Whitcomb and Eason, 1964; Eason, 1964, 1969; Rovner, 1973). Whitcomb and Eason (1964) reported the duration of egg incubation in wolf spiders could be monitored easily in the egg sac because lycosids will mend egg sacs that have been opened for inspection.

An important facet of the maternal care by lycosid females is opening the egg sac to facilitate the emergence of young. The wolf spider rotates the egg sac with her legs and palps and cuts the seam of the egg sac with her chelicerae. Few wolf spider young have been observed to emerge from an egg sac without the aid of the female (Eason, 1964). Eason noted that female lycosids with young or with an egg sac from which spiderlings are due to emerge would "adopt" spiderlings of the same species from another egg sac. Unmated females with no egg sac were not as receptive to such spiderlings. Eason successfully exchanged egg sacs between females.

The Green Lynx Spider, Peucetia viridans Hentz, displays maternal care behavior (Whitcomb, et al., 1966). The female Green Lynx, like the lycosids, aids the emerging young by opening the egg sac along a seam with her chelicerae. Whitcomb noted that, unlike the lycosids, spiderlings of $P$. viridans will emerge from the egg sac without maternal aid.

Descriptions of egg sac construction by $P$. viridans were reported by Whitcomb (1962) and Whitcomb, et al. (1966). The female usually constructs the first egg sac 21-28 days after mating. Egg sac

\footnotetext{
${ }^{1}$ Fla. Agricultural Experiment Station Journal Series No. 1036.

Manuscript received by the editor March 8, 1978.
} 


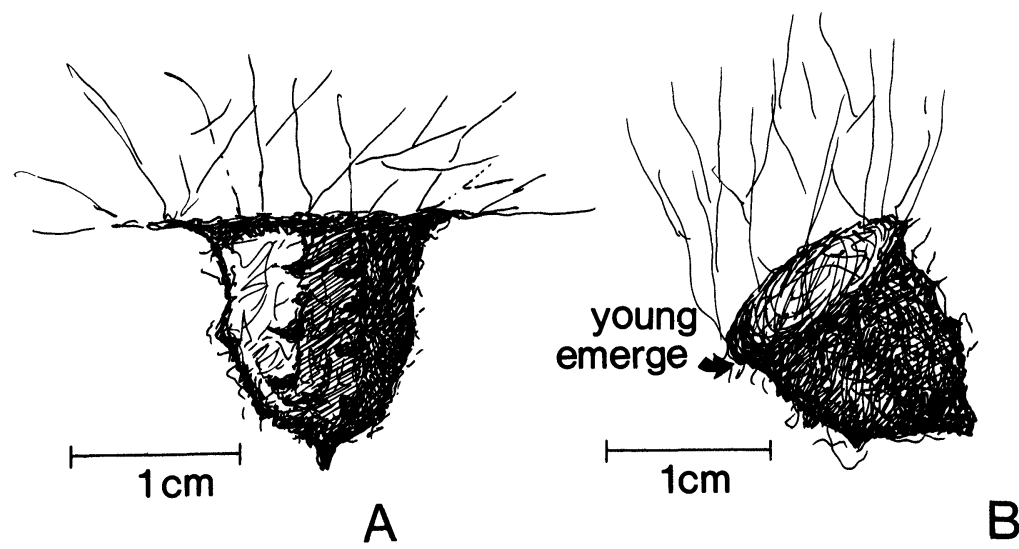

Figure 1. Peucetia viridans. A, newly formed egg sac. B, egg sac after opening and tilting by the female (arrow indicates lowest bowl/lid juncture).

construction is initiated by the spider spinning a silk disc under which a silk bowl with an opening in the bottom is formed. The egg sac is oriented in the upright position (Fig. 1A). The female forces eggs up into the bowl and seals the egg sac when oviposition is completed. The eggs hatch in 11-16 days depending on temperature and the spiderlings emerge from the egg sac 10-13 days after hatching.

\section{METHODS}

During early September 1974, 63 adult female $P$. viridans without egg sacs were collected. The spiders were maintained individually in the laboratory. The rearing containers were examined daily for the presence of egg sacs.

Egg sacs collected from the laboratory specimens were used to establish three distinct groups of egg sacs. The establishment of the experimental groups is described below.

GROUP I: Egg sacs without maternal care.

On 16 October 197410 female $P$. viridans constructed egg sacs. The egg sacs were removed in separate containers. Group I egg sacs went through development without an adult female ever being present. 
GROUP II: Egg sacs with maternal care.

On 17 October 1974 seven females constructed egg sacs and on 19 October 1974 three more females constructed egg sacs. The Group II egg sacs were allowed to remain with the females until the emergence of young.

GROUP III: Egg sacs with "adepted" maternal care.

A 3rd group of 10 egg sacs was collected on 28 October 1974. These egg sacs were taken from the females who had made them. Each egg sac was then placed in a rearing container that housed one of the females that had been removed from the Group I egg sacs. The Group III egg sacs were now with females whose own young were due to emerge in approximately 12 days but the young of the Group III egg sacs were not due to emerge for approximately 24 days. Thus these females had adopted egg sacs that were 12 days behind the schedule of the female's own egg sacs.

\section{RESULTS AND DISCUSSION}

The average duration of incubation and 1st stadia spent in the egg sac for the groups studied was: Group I -25.25 days; Group II -23.6 days and Group III -22.6 days with ranges of $21-28$, 22-29 and 20-26 days respectively; all falling within the time range as reported by Whitcomb, et al. (1966). Only two of the $30 \mathrm{egg}$ sacs were found to contain dead 2 nd instar spiderlings. I believe in handling those two egg sacs it was very possible that excess silk normally holding the egg sac in foliage held the lid to the bowl of the egg sac in such a way as to make emergence of young impossible.

The female Green Lynx Spider aids in emergence of young by tearing the egg sac shortly after the 1st deutova (1st instar - without tarsal claws, mouthparts or functional eyes) have molted. She inserts her chelicerae between the bowl and the lid and pulls the bowl away from the lid (Whitcomb, et al., 1966). The females of groups II and III displayed the maternal care described above, and performed one previously unreported behavior - the adult females tilted the egg sacs at an angle from $40^{\circ}-80^{\circ}$ after opening the egg sac and prior to the 1 st emergence of young. The egg sacs were tilted with the recently-made opening on the lowest side. The 


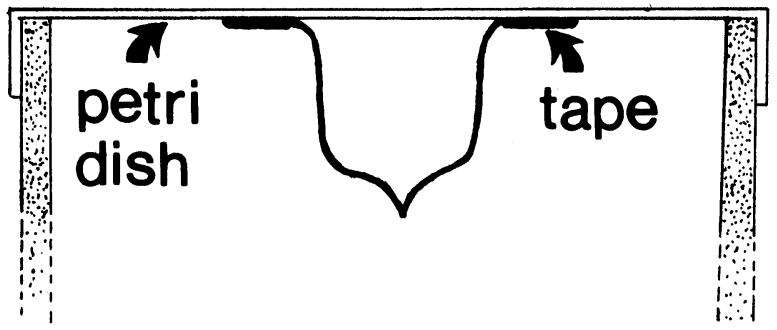

Figure 2. Technique used to prevent tilting of the egg sac.

Group II and Group III females tilted their egg sacs 6.4 and 6.1 days respectively, prior to the emergence of young; both groups with a range of 5-8 days. Due to the bowl shape, the egg sacs of Group I were tilted throughout development because of their position in plastic vials.

The young from all three groups emerged from the tilted egg sacs at the lowest bowl/lid juncture of the egg sac (Fig. 1B). Group I spiderlings opened the egg sac from within.

At this point in the investigation 15 more egg sacs were taken from the laboratory colony. Five egg sacs were taken from the females and taped to the underside of a petri dish lid, Fig. 2, thus making tilting of the egg sacs impossible. The remaining 10 egg sacs were allowed to remain with the females until after the females had opened and tilted the egg sacs. After opening and tilting had occurred five egg sacs were removed from the female and taped to a petri dish lid as described above. The remaining five egg sacs were taken from the females and artificially tilted with the opening made by the females at the highest point of the tilted egg sacs.

Young from all 10 untilted egg sacs emerged but not from the bowl/lid juncture as described for Groups I, II and III. Instead the young emerged in all directions from the bowl in an average 28.6 days compared to an average 24.6 days for the opened and tilted egg sacs of Groups II and III and the tilted egg sacs of Group I.

The young from the five egg sacs that had been artificially tilted with the opening at the highest point emerged from both the lowest bowl/lid juncture and from the opening made by the female. 


\section{CONCLUSION}

Young $P$. viridans are able to emerge from their egg sacs without the aid of an adult female (Group I and untilted egg sacs). The adult female Green Lynx opens and tilts her egg sac approximately six days prior to the emergence of young. The opening and tilting of the egg sac is the primary maternal care comprising emergence aid. Other maternal care exhibited by $P$. viridans includes pre- and post-emergence protection.

Emergence of young from the lowest bowl/lid juncture in tilted egg sacs and all directions from the bottom of the bowl in nontilted egg sacs would seem to indicate that gravity may play a role in the site of egg sac exit by young Green Lynx Spiders.

Emergence aid by an adult female made it possible for the young to emerge quicker than young where no emergence aid (tilting) was given. Tilting of the egg sac prior to emergence was in itself an aid but tilting of the egg sac was not a requirement for the young to emerge successfully. The adaptive significance of maternal care by the Green Lynx Spider is a higher percentage of young emerging from tilted egg sacs than from non-tilted. Although the number of young emerging was not documented, upon inspection of all the egg sacs cannibalism was in evidence in only the non-tilted egg sacs. Apparently the four extra days, on the average, spent in the non-tilted egg sacs resulted in cannibalism thereby reducing the percentage of young emerging from those egg sacs. No cannibalism was detected in the tilted egg sacs.

The females of Group III not only adopted another female's egg sac but opened and tilted their adopted egg sacs at the precise time they would have had they been their own eggs. These females would have opened and tilted their own egg sacs approximately 12 days earlier but waited for what is most logically a cue from within the egg sac. The cue was most likely the activity of the new 2nd instar spiderlings.

These findings are in contrast to those of Engelhardt (1964) who reported the maternal care exhibited by spiders of the genus Trochosa Koch (Lycosidae). He noted that like other lycosids Trochosa females must open the egg sac in order for the young to emerge successfully. The young are not able to hatch if the egg sac is opened too early. On the other hand, the egg sac must be opened no later than three days after the young have molted to the nymph 
I stage. Unlike $P$. viridans the opening of the egg sac by adult female Trochosa is not triggered by a stimulus from the egg sac or the spiderlings in it. Engelhardt considers the opening of Trochosa egg sacs to be regulated by endogenous neurosecretory function, related to oviposition and influenced by temperature in the same manner as the development of the eggs and spiderlings in the egg sac.

\section{ACKNOWLEDGEMENTS}

I sincerely thank Dr. Willard Whitcomb for his generous guidance during this investigation. I also thank Dr. Jonathan Reiskind for his interest in my work and for reading and discussing the manuscript for this report.

\section{REFERENCES}

EASON, R.

1964. Maternal care as exhibited by wolf spiders (Lycosids). Ark. Acad. Sci. Proc. 18: 13-19.

1969. Life history and behavior of Pardosa lapidicina Emerton (Araneae: Lycosidae). J. Kan. Entomol. Soc. 42(3): 339-360.

ENGELHARDT, W.

1964. Die mitteleupropäischen Arten der Gattung Trochosa C. L. Koch, 1848 (Araneae, Lycopidae). Morphologie, Chemotaxonomie, Biologie, Autökologie. Z. Morph. Ökol. Tiere 54: 219-392.

ROVNER, J. S.

1973. Maternal behavior in wolf spiders: The role of abdominal hairs. Sci. 182: 1153-1155.

Wнітсомв, W. H.

1962. Egg sac construction and oviposition of the green lynx spider, Peucetia viridans (Oxyopidae). Southwestern Natur. 7(3-4): 198-201.

Whitcomb, W. H., AND R. EASON.

1964. A technique for determining the duration of egg incubation in wolf spiders. Turtox News 42(12): 301-302.

Whitcomb, W. H., M. Hite, and R. Eason.

1966. Life history of the green lynx spider, Peucetia viridans (Araneida: Oxyopidae). J. Kan. Entomol. Soc. 39(2): 259-267. 

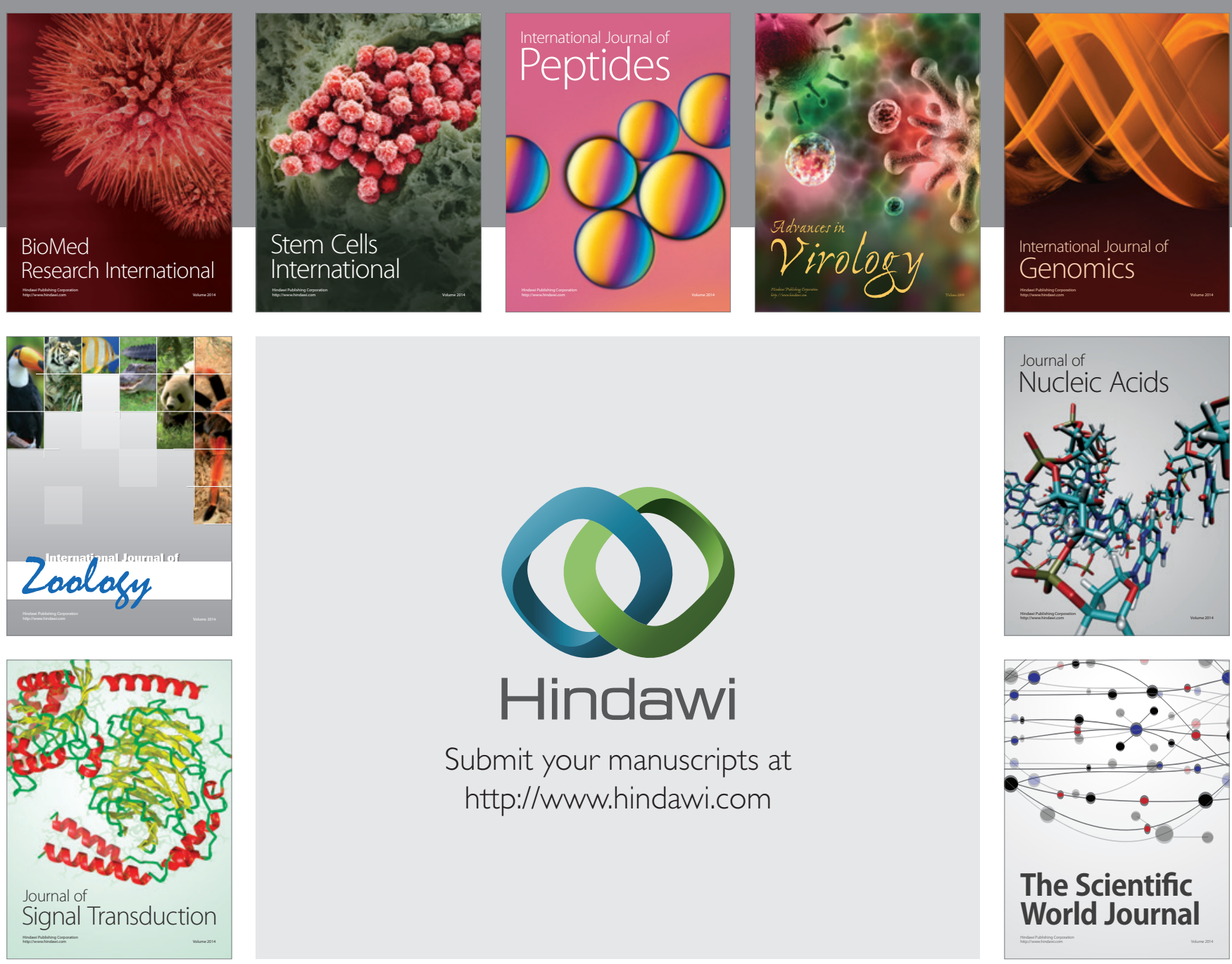

Submit your manuscripts at

http://www.hindawi.com
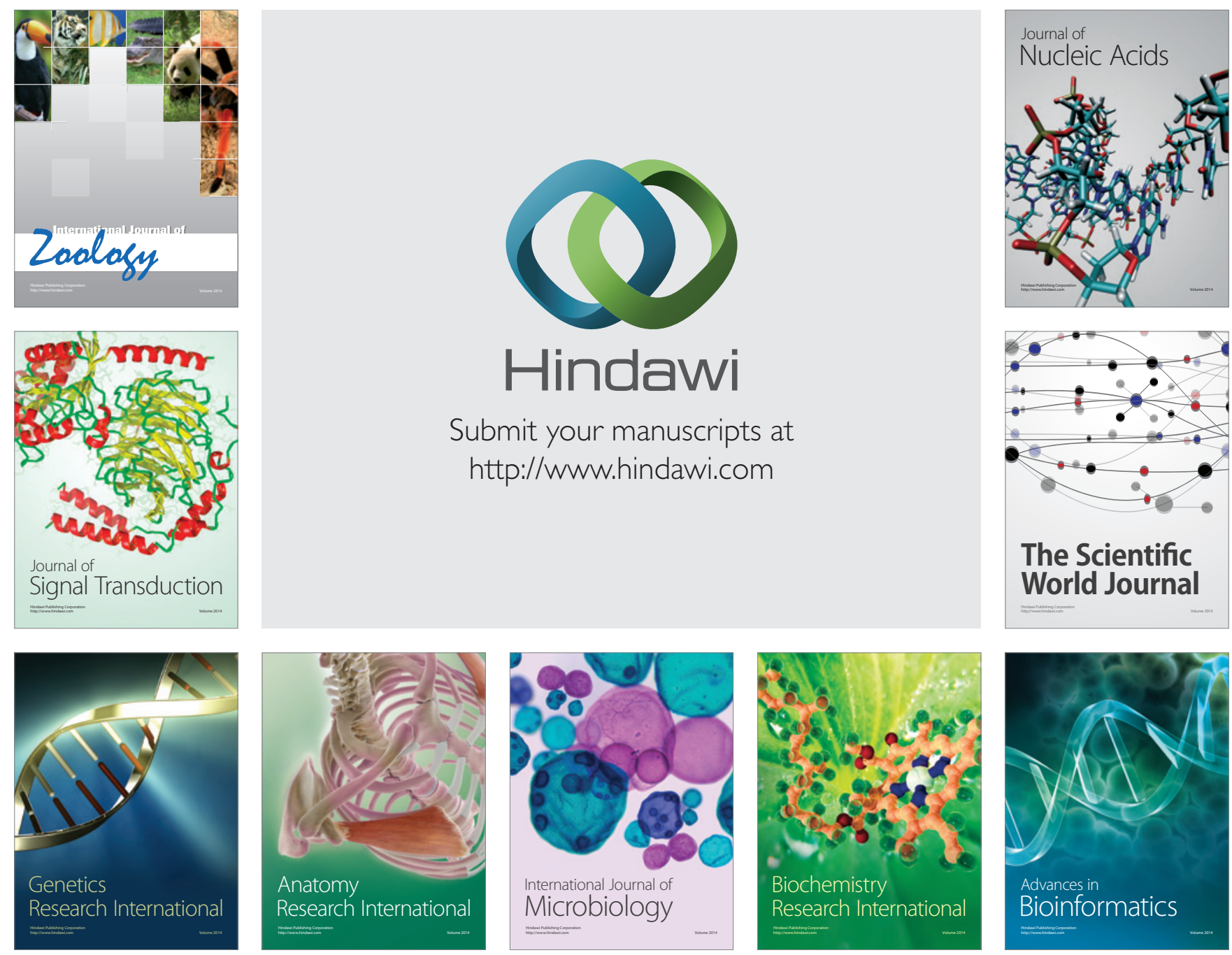

The Scientific World Journal
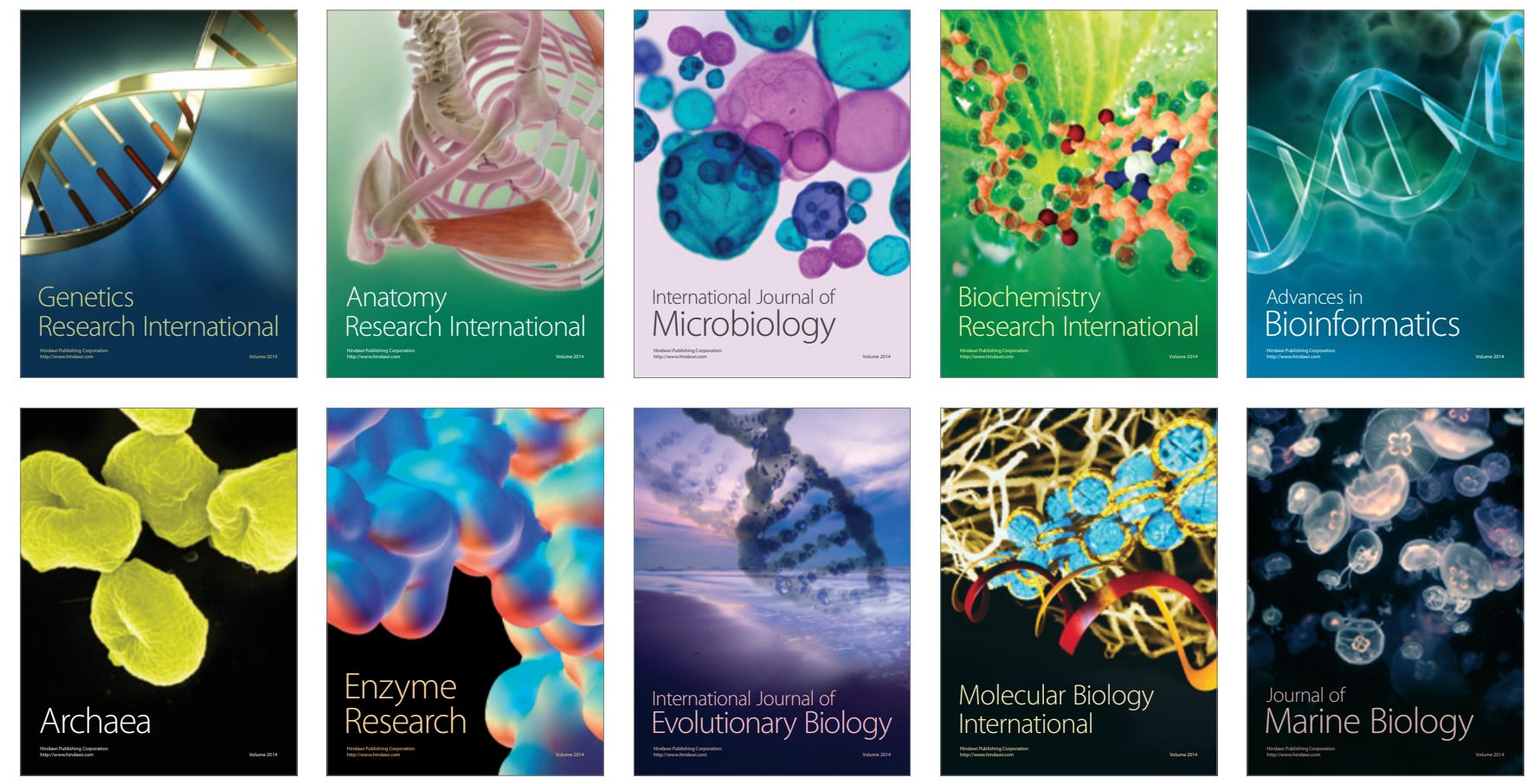